\title{
Meet the editors
}

\author{
Like all journals based on Nature's editorial philosophy, Nature Physics relies on a dedicated team of \\ full-time editors. We briefly describe who they are and what they do.
}

It is a peculiar aspect of living things that they have the capacity to regenerate themselves. An important biological organ such as your liver lasts a (human) lifetime, whereas the cells that make it up have much shorter lifespans, on the order of 400 days. Indeed, this turnover of cells appears to be an essential factor that allows the tissue they are a part of to, well, live. A similar phenomenon also occurs in social systems: villages, cities, institutions, religions and entire cultures can 'live' for centuries, whereas the humans that make them up, clearly, don't.

Earlier this year, Nature Physics completed its first editorial turnover cycle: following May Chiao's departure to launch Nature Astronomy, our own journal's team no longer contains any of the original members that launched it. Of course, Nature Physics continues to live and, we hope, will continue to do so for a long time after the current crop of editors moves on. Nevertheless, this seems like a good excuse to present this new generation of editors, and while we're at it, perhaps briefly describe what their roles entail.

A principal distinction between a Nature journal and its societal counterparts is that we have no editorial board made up of practicing academics. Instead, the editorial prerogative is exercised entirely by full-time, professional editors that are employed by our parent company, Springer Nature. This means we are expected to turn a profit - an issue that falls squarely under the responsibility of our publisher, and without which we would not be a viable business. However, it also means that we are independent from the direct influence of any university, society or funding agency - our interests are very much aligned with the objective to publish the best science we can, regardless of the country or laboratory it comes from.

Each editor in the team covers a brief that spans a number of physics subdisciplines. Abigail Klopper handles soft condensed-matter physics and biophysics. Iulia Georgescu handles optical physics and photonics, as well as taking care of submissions in astronomy and high-energy physics. Condensed-matter physics - a huge area of research that accounts for roughly a third of our submissions - is handled

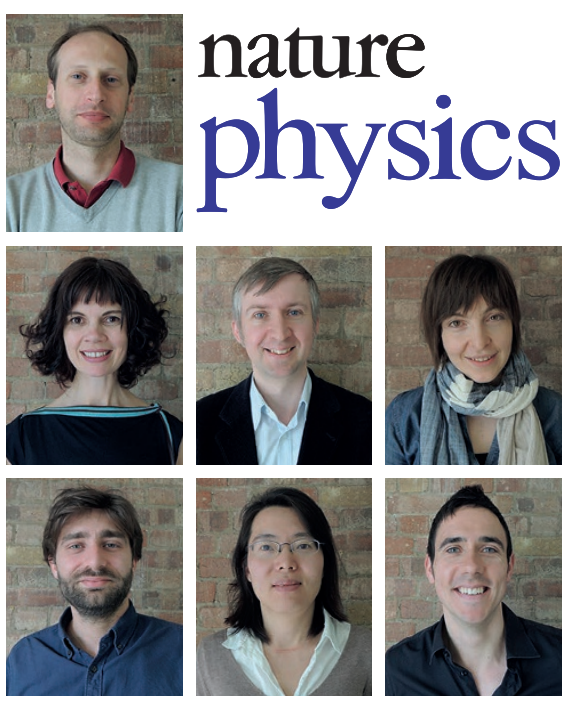

by Luke Fleet (whose interests include magnetism and superconductivity, as well as device physics) and Bart Verberck (whose brief also extends into the area we refer to as laser-matter interactions, and through this also into plasma physics). Andrea Taroni has a background in condensed-matter physics and statistical physics, and typically handles papers that straddle these areas.

Recently, we also welcomed two new additions to the team. Yun $\mathrm{Li}$ joins us from Swinburne University in Melbourne, Australia, and - in what represents a first for us - will be based in our Shanghai office. She will oversee submissions in atomic and molecular physics (including cold atoms), and aspects of quantum physics. And later this month, Federico Levi (who already had a brief stint with us in 2014) will join us from Nature Communications. His brief will include re-invigorating our offering in the area of complexity and, with the support of Yun and Iulia, quantum technologies.

Our editorial makeup reflects the international nature of scientific research: between the seven of us, we hold six different nationalities and speak 11 languages. More importantly, it also reflects the breadth, depth and variety of physics as a discipline - something we are keen to cultivate and showcase in each one of our issues.

So what, exactly, is it that the editors do? In plain terms, they are the champions for the fields that they handle, both at the journal and within Springer Nature more broadly. They are driven by the same passion for learning that inspires practicing scientists - indeed, all of our editors have a background in research - but it is fair to say that this is complemented by an interest in communicating science and unpacking its latest developments as accurately and concisely as possible.

In practice, much of our time is spent handling submitted manuscripts. Yes, as part of this we turn down many excellent submissions, so in addition to providing feedback as rapidly as possible, we also endeavour to help authors find a home for their manuscript, perhaps at our open-access sister publication, Nature Communications. But we are also responsible for the fraction of papers that we send out for review, by liaising with reviewers selected on the basis of their expertise, and authors, whom we may contact with detailed requests for additional analysis and clarification in their revised manuscripts. If all goes well, we shepherd these papers towards publication. We are also fortunate to have in-house art editors and production editors; these colleagues help us ensure that our published papers look as good as possible.

Editors also do a lot of travelling. Whether it is for a conference or a lab visit, these trips are valuable opportunities to learn about the latest developments in any given field, as well as maintain and develop links with our authors and reviewers. They also help provide us with ideas for the 'magazine' part of the journal, the section in which we publish commentary and opinion on recent trends in physics and science policy. Finally, we also write a monthly leader column, as well as curating a regular Books \& Arts section.

Be that as it may, for all the editors' work, Nature Physics would not exist without the continued support and good will of the wider physics research community. We could not function without the trust that underpins the peer-review process that we manage, let alone the vital and largely underappreciated advice we receive from our reviewers. Along with our authors and readers, we also take this opportunity to say thank you. 